\title{
Testosterone Differentially Affects T Cells and Neurons in Murine and Human Models of Neuroinflammation and Neurodegeneration
}

\author{
Megan G. Massa, * Christina David, ${ }^{*}$ Stefanie Jörg, ${ }^{\dagger}$ Johannes Berg, ${ }^{*}$ Barbara Gisevius, ${ }^{*}$ Sarah Hirschberg, ${ }^{*}$ Ralf A. Linker, \\ Ralf Gold, ${ }^{*}$ and Aiden Haghikia*
}

From the Department of Neurology, * Ruhr University-Bochum, Bochum; and the Department of Neurology, ${ }^{\dagger}$ Friedrich-Alexander University-ErlangenNuremberg, Erlangen, Germany

Accepted for publication

March 22, 2017.

Address correspondence to Aiden Haghikia, M.D., Department of Neurology, Ruhr University-Bochum, St. Josef Hospital-Bochum, Gudrunstr. 56, 44791 Bochum, Germany. E-mail: aiden.haghikia@ rub.de.

\begin{abstract}
The high female-to-male sex ratio of multiple sclerosis (MS) prevalence has continuously confounded researchers, especially in light of male patients' accelerated disease course at later stages of MS. Although multiple studies have concentrated on estrogenic mechanisms of disease modulation, fairly little attention has been paid to androgenic effects in a female system, and even fewer studies have attempted to dissociate hormonal effects on the neurodegenerative and neuroinflammatory processes of MS. Herein, we demonstrate the differential effects of hormone treatment on the acute inflammatory and chronic neurodegenerative phases of murine experimental autoimmune encephalomyelitis. Although s.c. treatment with testosterone and aromatase inhibitor applied beginning on the day of immunization ameliorated initial course of disease, similar treatment administered therapeutically exacerbated chronic disease course. Spinal cord analyses of axonal densities reflected the clinical scores of the chronic phase. In vitro, testosterone treatment not only decreased Th1 and Th17 differentiation in an aromatase-independent fashion, but also exacerbated cell death in induced pluripotent stem cellderived primary human neurons under oxidative stress conditions in an aromatase inhibitordependent manner. Thus, through the alleviation of inflammatory processes and the exacerbation of neurodegenerative processes, androgens may contribute to the epidemiologic sex differentials observed in MS prevalence and course. (Am J Pathol 2017, 187: 1613-1622; http://dx.doi.org/10.1016/ j.ajpath.2017.03.006)
\end{abstract}

The female-to-male prevalence ratio of multiple sclerosis (MS) presently stands at 3:1, if not more; however, male MS patients tend to have not only a slightly later onset but also a more debilitating disease course than do their female counterparts, especially during the later stages of MS progression. ${ }^{1}$ Although environmental and genetic factors have been explored, ${ }^{2-4}$ much research attempting to elucidate this topic has been dedicated to sex steroid hormones. Although epidemiological and linkage studies have suggested a role of hormones in the disease, ${ }^{5-7}$ clinical trials in humans have provided further evidence of a direct influence of sex steroid hormones on the pathogenesis and disease course of $\mathrm{MS}^{8-12}$ Within these studies, the different effects of steroid hormone treatment on cognitive ability and gadolinium-enhancing lesions indicate a plausible dissociation between hormonal effects on the neurodegenerative and neuroinflammatory processes of MS. This conjecture is strengthened by findings from in vitro experiments demonstrating that the timing of hormone treatment to cellular stressor, ${ }^{13}$ strength of hormone treatment, ${ }^{14}$ type of cellular stressor, ${ }^{15}$ and strength of stressor $^{13}$ can result in differing cellular outputs. Indeed,

Partially supported by the Medical Faculty of the Ruhr UniversityBochum and a German-American Fulbright Commission Fulbright grant (M.G.M.).

M.G.M. and C.D. contributed equally to this work.

Disclosures: Miglyol $812 \mathrm{~N}$ oil was provided by Cremer Oleo (Witten, Germany). R.A.L. holds an endowed professorship supported by Novartis.

Current address of M.G.M., Interdepartmental Ph.D. Program for Neuroscience, UCLA, Los Angeles, California. 
such may provide a partial explanation of why female MS patients typically experience greater inflammatory lesions, whereas their male counterparts display more neurodegeneration.

This question of differential hormonal actions has yet to be fully explored within the context of MS. Most animal studies have treated the arguably biphasic disease as a single entity, ${ }^{16-18}$ and those that have teased apart the aforementioned processes have mostly focused on the beneficial estrogenic effects on immune system and myelin pathology. ${ }^{19-21}$ Similarly, although in vitro experiments have mostly confirmed positive estrogenic (typically via estradiol) effects on neuron survival ${ }^{2,23}$ and inflammation, ${ }^{24,25}$ the few investigations into androgenic effects have achieved less consensus. Though most in vitro inflammation research has demonstrated convincing evidence of pure androgenic protection via the induction of anti-inflammatory cell profiles, ${ }^{26-28}$ congruent studies on neurodegeneration and protection have resulted in conflicting results ${ }^{29-31}$ or findings have been confounded by the potential conversion of testosterone to estradiol within a given system. ${ }^{13}$

Thus, to uncover the contribution of androgens to MS and experimental autoimmune encephalomyelitis (EAE) disease course, experiments conducted in vivo must dissociate neurodegeneration from inflammatory processes, whereas those in vitro ought to use disease-appropriate paradigms. Here, we successfully dissociate these two aforementioned processes in vivo and investigate androgen specificity on these with the coapplication of testosterone and the aromatase inhibitor fadrozole to prevent endogenous estradiol conversion. Strategically-timed hormonal treatments targeting the acute (inflammatory) or chronic (neurodegenerative) phases of the $\mathrm{C} 57 \mathrm{Bl} / 6$ murine, myelin oligodendrocyte protein (Mog)induced MS model $\mathrm{EAE}^{20}$ revealed an androgen-mediated alleviation of inflammation and exacerbation of neurodegeneration. In vitro murine T-cell differentiations along with oxidative stress-induced neurodegeneration assays in human primary neuron cultures derived from induced pluripotent stem cells have confirmed these differential androgenic effects.

Herein, we describe how androgens differentially affect the inflammatory and neurodegenerative processes in the context of EAE and in vitro models.

\section{Materials and Methods}

\section{Animals}

Gonadally intact female C57BL/6J mice, aged 7.5 to 10 weeks, were obtained from Charles River (Sulzfeld, Germany) or Janvier (Saint-Berthevin, France) and maintained under a 12:12-hour light-dark schedule. All experiments were conducted with the approval of the Regulatory Authority of the Federal State North-Rhine Westfalia handling all cases dealing with environment and consumer protection (study reference number 84-02.04.2015.A259).

\section{Active EAE Induction}

Mice were immunized by two 5- $\mu \mathrm{L}$ bilateral s.c. flank injections containing 50 $\mu \mathrm{g}$ Mog 35-55 peptide (Charité, Berlin, Germany) and $50 \mu \mathrm{g}$ complete Freund's adjuvant (Difco Laboratories, Detroit, MI) in a 1:1 solution of phosphate-buffered saline (PBS) and incomplete Freund's adjuvant (BD, Heidelberg, Germany). Immediately after and 2 days after immunization, mice received $100 \mu \mathrm{L}$ i.p. PBS injections containing $0.2 \mu \mathrm{g}$ pertussis toxin (Millipore, Darmstadt, Germany).

\section{Adoptive Transfer EAE Induction and Mog Rechallenge}

Mice were actively immunized as described in Active EAE Induction, though total Mog and complete Freund's adjuvant injected were $400 \mu \mathrm{g}$ and $100 \mu \mathrm{g}$, respectively. After daily hormone treatments (Hormone Treatments), spleen and lymph nodes were isolated on the 9th day after immunization (D9) and cells cultivated in restimulation medium (RPMI supplemented with $1 \%$ pen/strep, $1 \%$ nonessential amino acids, $100 \mathrm{mmol} / \mathrm{L}$ sodium pyruvate, $200 \mathrm{mmol} / \mathrm{L} \mathrm{L}$-glutamine, $10 \%$ fetal calf serum, and 50 $\mu \mathrm{mol} / \mathrm{L} \beta$-mercaptoethanol). Cells were first stimulated with $50 \mu \mathrm{g} / \mathrm{mL}$ Mog, $25 \mathrm{ng} / \mathrm{mL}$ IL-12, and $10 \mu \mathrm{g} / \mathrm{mL} \alpha$-IL-4, and after 24 hours $5 \mathrm{ng} / \mathrm{mL} \mathrm{IL-2}$ was added to the medium. On the 3rd day after isolation, 10 million cells in $500 \mu \mathrm{L}$ were i.p. injected into 15 female mice (8 weeks old; Janvier). Two animals per treatment group were sacrificed on D14 for CD3 and macrophage differentiation antigen (Mac3) quantification (IHC Analysis). The remaining animals were immunized with Mog and complete Freund's adjuvant as in the active immunization beginning on D13.

\section{Disease Severity Assessment}

Animals were weighed and scored daily based on a 10-point EAE scale: 0 indicates no signs of disease; 1 indicates reduced tail tone; 2 indicates entire tail tone lost; 3 indicates rolling gait and mild ataxia; 4 indicates rolling gait, moderate ataxia, and/or mild paresis of hind limbs; 5 indicates severe ataxia and paraparesis of hind limbs; 6 indicates severe paresis of both or complete paralysis of one hind limb; 7 indicates complete hind limb paralysis; 8 indicates forelimb weakness or tetraplegia; 9 indicates respiratory distress, moribund; and 10 indicates death.

\section{Hormone Treatments}

\section{Stock Solutions and Injections}

Testosterone (T) and the aromatase inhibitor fadrozole (FAD) were both obtained from Sigma-Aldrich (Hamburg, Germany). Stock solutions of $46.2 \mathrm{mmol} / \mathrm{L} \mathrm{T}$ and 77.0 $\mathrm{mmol} / \mathrm{L}$ FAD were prepared in $100 \%$ ethanol and stored at $-20^{\circ} \mathrm{C}$. Working solutions prepared in Miglyol $812 \mathrm{~N}$ oil (generously provided by Cremer Oleo, Witten, Germany) 
contained $10 \%$ ethanol and, where indicated, $4.16 \mathrm{mmol} / \mathrm{L}$ $\mathrm{T}$ and/or $0.77 \mathrm{mmol} / \mathrm{L}$ FAD. These concentrations yielded treatments of $60 \mu \mathrm{g}$ and $10 \mu \mathrm{g}$, respectively, as derived from previous studies. ${ }^{26,32}$ Vehicle controls contained $10 \%$ ethanol in either PBS (treatment in acute phase) or Miglyol $812 \mathrm{~N}$ oil (treatment in chronic phase). Injections of working solutions s.c. into the cervical area were accomplished using 23-gauge needles. To reduce inconstant hormone fluctuations, injections were administered within the same 3-hour window each day.

\section{Acute and Adoptive Transfer Treatment}

Animals were randomized into four groups $(\mathrm{T}, \mathrm{T}+\mathrm{FAD}$, $\mathrm{FAD}$, and vehicle) containing similar mean weights and housed together before EAE induction. Beginning on the day of immunization (day 0), mice were injected daily with hormone working solutions or PBS control. PBS was used as control due to the possibility of isolated oil treatment (composed of short-chain fatty acids) affecting inflammation $^{33}$; hormone treatment with oil overpowered this effect in treated animals. For active acute EAE, treatment was continued daily until sacrifice (days 27 to 30 ); for adoptive transfer, hormone treatments were given only to donor mice until sacrifice for transfer.

\section{Treatment in the Chronic Phase}

Animals were randomly, individually treated at the first sign of disease onset (days 8 to 14 after immunization) with either hormone injections ( $\mathrm{T}$ or T $+\mathrm{FAD}$ ) or Miglyol-based vehicle as control. Treatment was continued daily until sacrifice (days 43 to 44 ).

\section{Histologic Preparation}

At experiment termination, mice were deeply anesthetized with a narcotics solution containing $0.0375 \%$ Ventraquil (Ceva Sante Animale, Libourne, France), $1.8 \mathrm{mg} / \mathrm{mL}$ Xylavet (CP-Pharma, Burgdorf, Germany), and $37.5 \mathrm{mg} /$ mL ketamine (CP-Pharma) in $0.9 \%$ sodium chloride. Once reflexes became dormant, a transcardial perfusion was performed with $0.9 \%$ sodium chloride followed by $4 \%$ paraformaldehyde solution. Spinal cords, brain (excluding olfactory bulbs), and spleen were removed and submerged in $4 \%$ paraformaldehyde for 24 to 36 hours before 24 to 48 hours cryoprotection in PBS. Cassettes containing three sections of cervical, thoracic, and lumbar spine sections, as well as cassettes prepared with quartered brain slices, were subjected to serial dehydration using the TP1020 Semienclosed Benchtop Tissue Processor (Leica, Wetzlar, Germany). Tissue was subjected to ten 1-hour reagent baths $(50,70,80,90,95,3 \times 100 \%$ ethanol, and $2 \times$ Xylol) before paraffin wax bath. Cassettes were subsequently embedded in paraffin blocks using the EG1160 Embedding Center (Leica). Free-floating sections $(5 \mu \mathrm{m}$ thick) were sliced with a RM2155 Microtome (Leica) and mounted onto SuperFrost Plus slides (Gerhard Menzel,
Braunschweig, Germany) in preparation for staining and analyses.

\section{IHC Analysis}

Previously dehydrated, paraffin-embedded tissue was sectioned into 5- $\mu \mathrm{m}$ slices and subjected to rehydration via a descending alcohol series (beginning with xylene and followed by $99 \%, 90 \%, 80 \%, 70 \%$, and $50 \%$ ethanol submersions) before Bielschowsky silver impregnation, Luxol fast blue staining, or diaminobenzidine staining for $\mathrm{CD}^{+} \mathrm{T}$ cells and $\mathrm{Mac}^{+}$macrophages.

Axonal damage in spinal cord white matter was evaluated via silver staining procedures. Briefly, after sections were incubated with $10 \%$ silver nitrate for 20 minutes, cells were stored in distilled water $\left(\mathrm{dH}_{2} \mathrm{O}\right) ; 25 \%$ ammonia solution was added until solution clarity. Tissue sections were then incubated in the clear silver hydroxide solution for another 20 minutes. Slides were washed in $1 \%$ ammonia solution before being subjected to constant shaking and the addition of developer solution $(4.17 \mathrm{mg} /$ $\mathrm{mL}$ citric acid, $1.665 \%$ formaldehyde, and one drop $65 \%$

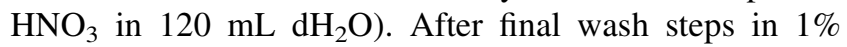
ammonia and $\mathrm{dH}_{2} \mathrm{O}$, slides were incubated in $5 \%$ sodium thiosulfate for 3 minutes before ascending alcohol series and coverslipping.

Luxol fast blue staining was used for observing demyelination within spinal cord white matter. Slides were initially incubated in Luxol fast blue staining solution overnight at $60^{\circ} \mathrm{C}$. Slides were then rinsed in $96 \%$ ethanol and $\mathrm{dH}_{2} \mathrm{O}$ before $0.05 \%$ lithium carbonate exposure. After this, sections were washed in $\mathrm{dH}_{2} \mathrm{O}$ and $70 \%$ ethanol before a 10 minute incubation with $0.8 \%$ periodic acid. Slides were subsequently counterstained with Schiff reagent for $40 \mathrm{mi}-$ nutes. Final washing steps with sulfite and flowing water and an ascending alcohol series preceded coverslipping.

Spinal cord infiltrates, namely $\mathrm{CD}^{+} \mathrm{T}$ cells and $\mathrm{Mac}^{+}$ macrophages, were visualized using diaminobenzidine staining. After antigen unmasking via a 35-minute bath in heated citrate buffer, sections were blocked with a $10 \%$ bovine serum albumin solution in PBS for 30 minutes. Slides were then incubated in the primary antibody solutions (1:200 in $1 \%$ bovine serum albumin in PBS) of either antiCD3 (Serotec, Düsseldorf, Germany) or anti-Mac3 (BD Biosciences, Heidelberg, Germany) overnight at $4^{\circ} \mathrm{C}$. This incubation was followed by a 15-minute bath in $3 \%$ hydrogen peroxide to block endogenous peroxidase activity. Incubation with the secondary, biotinylated antibody (biotinylated rabbit anti-rat, Vector Laboratories, Dossenheim, Germany; 1:200 dilution in 1\% bovine serum albumin in PBS) was performed over 1 hour, followed by incubation with an avidin-biotin complex (Vectastain ABC Kit; Vector) according to the manufacturer's instructions. Tissue was then transferred into diaminobenzidine staining solution for 10 minutes and counterstained with hematoxylin at a 1:1 dilution in $\mathrm{dH}_{2} \mathrm{O}$ for 20 seconds. Sections were washed in 
flowing water before ascending alcohol series exposure and coverslipping.

\section{Microscopy and Analysis}

To quantify the impact of androgens on spinal cord axonal preservation, demyelination, and T-cell/macrophage infiltration, nine independent spinal cord cross sections per specimen were analyzed. Demyelination was quantified semiautomatically using CellD software version 2.6 (Olympus, Hamburg, Germany), and was defined as the ratio to total white matter area. Axonal densities were determined by axon counting of profiles in three lesions per section on a $100-\mathrm{mm}$-diameter grid at $1000 \times$ magnification. Cellular infiltrates were counted in three visual fields within each of the cervical, thoracic, and lumbar sections as captured at $20 \times$ magnification (image size $264.6 \times 356.6$ $\mu \mathrm{m})$ and multiplied by a factor of 10.6 to determine the number of cells per square millimeter.

\section{Murine Th1/Th17 Differentiation}

Splenic T cells were isolated with magnetic activated cell sorting via the Pan T Cell Isolation Kit II (Miltenyi Biotec, Bergisch Gladbach, Germany) according to the manufacturer's instructions, using 30 million cells. For naïve differentiations, cells were fluorescently stained for 30 minutes in an antibody cocktail containing $\alpha \mathrm{CD} 4$-fluorescein isothiocyanate (eBioscience, Frankfurt, Germany), $\alpha \mathrm{CD} 44$-phycoerythrin (BioLegend, London, UK), $\alpha \mathrm{CD} 62 \mathrm{~L}$-antigen-presenting cells (eBioscience), and $\alpha \mathrm{CD} 25$-phycoerythrin-Cy5 (eBioscience). Naïve cells were subsequently isolated by fluorescence-activated cell sorting with MoFlo (Beckman Coulter, Krefeld, Germany) and the fluorescence-activated cell sorting-core in the department of neurology, in the neuroimmunological laboratory of the University of Erlangen. For Th17 differentiation, sorted naïve T cells $\left(\mathrm{CD} 4{ }^{+} \mathrm{CD} 26 \mathrm{~L}^{+} \mathrm{CD} 44^{\text {low }} \mathrm{CD} 25^{-}\right)$were stimulated by 2 $\mu \mathrm{g} / \mathrm{mL}$ plate-bound anti-CD3 (BD Biosciences) and $2 \mu \mathrm{g} / \mathrm{mL}$ anti-CD28 (BD Biosciences) in the presence of $40 \mathrm{ng} / \mathrm{mL}$ IL-6 and $1 \mathrm{ng} / \mathrm{mL}$ recombinant human transforming growth factor $\beta_{1}$ for 4 days. For Th1 differentiations, sorted naïve $\mathrm{CD} 4^{+} \mathrm{T}$ cells were incubated at $37^{\circ} \mathrm{C}, 5 \% \mathrm{CO}_{2}$ for 96 hours with anti-CD3, anti-CD28, $20 \mathrm{ng} / \mathrm{mL}$ IL-12, and $10 \mathrm{mg} / \mathrm{mL}$ anti-IL-4 (BioLegend). To determine the influence of testosterone on T-cell differentiation, three independent platings of cells were cultured with and without 1,10 , and $100 \mathrm{nmol} / \mathrm{L} \mathrm{T}$. To ensure the observed hormonal effects were androgenic in nature, $5 \mu \mathrm{mol} / \mathrm{L} \mathrm{FAD}^{34}$ was simultaneously applied in one experiment.

For intracellular flow cytometry, cells were stimulated for 4 hours with $1 \mu \mathrm{mol} / \mathrm{L}$ ionomycin and $50 \mathrm{ng} / \mathrm{mL}$ phorbolmyristate-acetate in the presence of $2 \mu \mathrm{mol} / \mathrm{L}$ monesin and stained for CD4 (eBioscience), intracellular IL-17A (eBioscience), and interferon- $\gamma$ (eBioscience). The fixable viability dye eFluor780 (0.2 $\mu \mathrm{L} /$ test; Thermo Fisher Scientific, Darmstadt, Germany) was used for excluding dead cells.

\section{Human Neuron Cell Culture}

Primary human neuron cultures were cultured from renal cells found in female healthy control donor urine via an induced pluripotent stem cell procedure as previously described. ${ }^{35}$

\section{Apoptosis Assay}

Previously frozen cells were plated directly onto poly-Lornithine hydrobromide/laminin-coated 96-well plates (5000 to 10,000 cells per well) at least 3 days before testing. By testing date, all neurons were at least 20 days old. Oxidative stress $\left(15 \mu \mathrm{mol} / \mathrm{L} \mathrm{H}_{2} \mathrm{O}_{2}\right)$ was applied for 4 to 5 hours before the application of hormone treatment $(10,100$, or $1000 \mathrm{nmol} / \mathrm{L} \mathrm{T}$ with or without $5 \mu \mathrm{mol} / \mathrm{L} \mathrm{FAD,} 0.015 \%$ ethanol). After 24 hours of $\mathrm{H}_{2} \mathrm{O}_{2}$ exposure and 19 to 20 hours of hormone treatment, cells were washed once before the application of $4 \mu \mathrm{g} / \mathrm{mL}$ Hoechst solution. After a 2-hour incubation, $0.5 \mu \mathrm{L} 7$-aminoactinomycin $\mathrm{D}$ viability stain per well was added for 10 minutes before fluorescent microscopy. Because Hoechst integrates into cell DNA regardless of cell status, whereas 7-aminoactinomycin D binds DNA only on membrane fractionation, apoptotic cells are doublestained. Cells were analyzed via cell counting at $20 \times$ magnification, with three visual fields pooled from each well. All conditions had $n \geq 3$ with triplicates. Data are presented as percent double-stained of total Hoechst-stained nuclei.

\section{Statistical Analysis}

All statistical analyses were performed with Prism software version 6 (GraphPad Software, La Jolla, CA). Three individual EAE experiments were performed, and data from the same condition were pooled for clinical scoring and immunohistochemistry analysis. EAE score data were analyzed via Kruskal-Wallis test followed by Dunn multiple comparisons test; in vitro and histologic data by one-way analysis of variance and subsequent Sidak multiple comparisons. One T-regulatory cell (Treg) and three independent Th1/Th17 differentiation experiments were normalized to means of control triplicates before pooling.

\section{Results}

\section{$\mathrm{T}+\mathrm{FAD}$ Alleviates Acute and Exacerbates Chronic EAE Disease Course}

To target the acute inflammatory or chronic neurodegenerative phases of EAE, hormone treatments - control, T, and $\mathrm{T}$ with the aromatase inhibitor FAD-were administered daily from the day of disease induction and the day of first sign of disease, respectively.

There was a significant difference among hormone treatments within the regimens for both the acute $\left[\mathrm{H}_{(2)}=\right.$ 


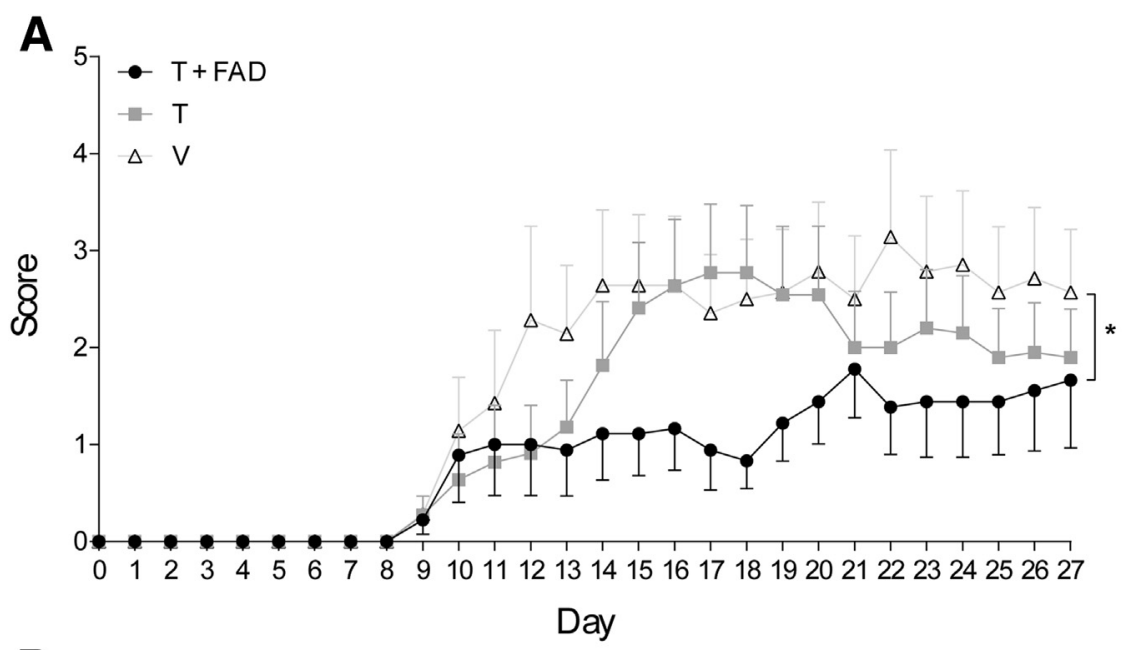

B

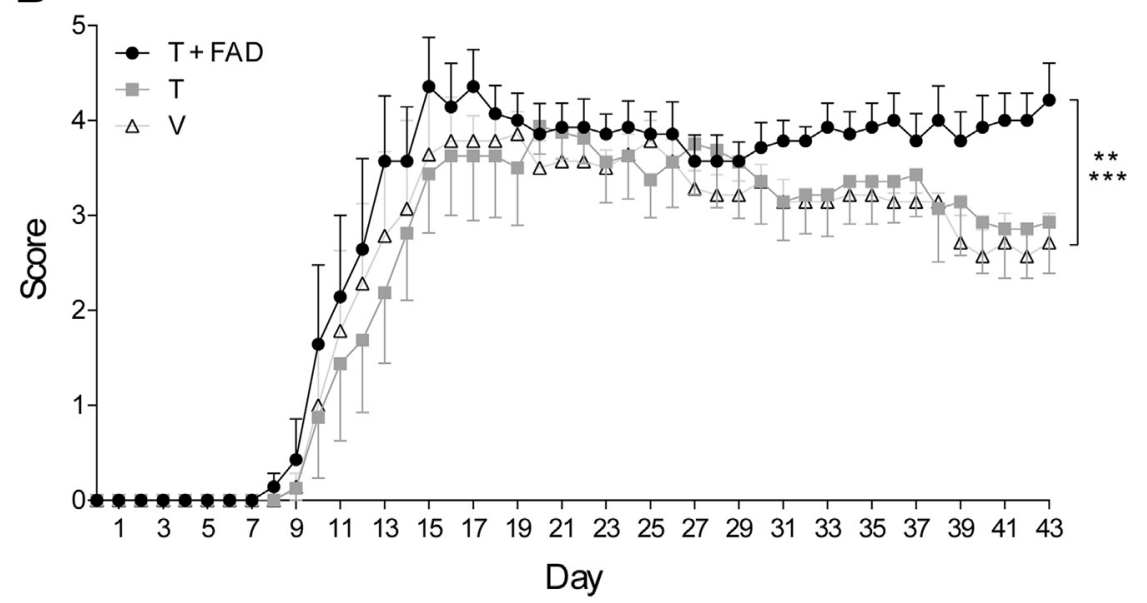

Figure 1 Effects of testosterone + fadrozole $(T+F A D)$ versus $T$ monotherapy on acute and chronic experimental autoimmune encephalomyelitis (EAE). A: Application of hormone treatment starting on the day of immunization (D0) shows an overall significant interaction between EAE score (treatment effect) and time. Follow-up Dunn multiple comparisons test reveals a significant alleviation of disease course with T + FAD treatment relative to vehicle control (V). B: With hormone treatment beginning on the day of symptom onset (D8 to D14), there is an overall significant interaction between EAE score (treatment effect) and time. Contrasting the acute phase, follow-up tests show a significant exacerbation of disease course with $T+F A D$ treatment, with regard to both $T$ treatment and vehicle control. Data are expressed as means \pm SEM. $n=7(\mathbf{A}, \mathbf{V}$, and $\mathbf{B}$, $\mathrm{T}+\mathrm{FAD}$ and $\mathrm{V}) ; n=8(\mathrm{~B}, \mathrm{~T}) ; n=9(\mathrm{~A}, \mathrm{~T}+\mathrm{FAD})$; $n=11(\mathbf{A}, \mathrm{T}) .{ }^{*} P<0.05,{ }^{*} P<0.01$, and $* * * P<0.001 . P=0.0229(\mathbf{A}, \mathrm{T}+\mathrm{FAD}$ versus $\mathrm{V})$; $P=0.0006(\mathrm{~B}, \mathrm{~T}+\mathrm{FAD}$ versus $\mathrm{V}) ; P=0.0024$ (B, $T+F A D$ versus $T)$.
7.145, $P=0.0281]$ and chronic $\left[\mathrm{H}_{(2)}=16.77, P=\right.$ 0.0002 ] phases. When administration was begun on the day of immunization, T + FAD alleviated disease course with regard to control $(P=0.0229)$; however, $\mathrm{T}+\mathrm{FAD}$ treatment begun on the day of individual symptom onset exacerbated EAE compared with both $\mathrm{T}$ treatment $(P=$ $0.0024)$ and vehicle $(P=0.0006)$ (Figure 1). Interestingly, neither hormone treatment had any effect on the number of T-cell or macrophage spinal cord infiltrates per square millimeter in the acute phase [tissue collected after the acute phase on day 27 after immunization; $F_{(2,6)}=0.4393, P=$ 0.6637] (data not shown); however, the treatment regimen significantly decreased relative axonal densities $\left[F_{(2,1017)}=\right.$ 3.473, $P=0.0314]$ and increased demyelination $\left[F_{(2,325)}=8.601, P=0.0002\right]$ in the chronic phase. Although only $\mathrm{T}+$ FAD resulted in decreased axonal densities $(P=0.0285)$, both the $\mathrm{T}+\mathrm{FAD}(P=0.0001)$ and $\mathrm{T}(P=0.0171)$ treatment regimens increased demyelination (Figure 2).

To further isolate the immune reactive stage, an adoptive transfer experiment was performed. Hormone treatment of donor mice had no effect on T-cell and macrophage infiltration, similar to active acute $\mathrm{EAE}\left[\mathrm{H}_{(2)}=0.6087\right.$ and
5.623, $P=0.0536]$, and none of the mice displayed signs of ailment (Supplemental Figure S1). After Mog restimulation on D13 in the remaining mice, resulting disease courses showed no effect of donor cell treatment $\left[\mathrm{H}_{(2)}=\right.$ 2.157, $P=0.341$ ] (Supplemental Figure S1).

\section{T Treatment in Vitro Decreases Murine Th1 and Th17 Cell Differentiation Independent of Aromatization}

Because T + FAD treatment alleviated the clinical course of EAE during the acute phase but did not alter T-cell and macrophage infiltration, ex vivo T-cell differentiation assays were performed. As MS autoimmunity is believed to be mediated by a surplus of proinflammatory Th1 and Th17 cells relative to Treg cells, ${ }^{36}$ naïve murine splenic $\mathrm{T}$ cells were isolated and subjected to Th1-, Th17-, and Tregpolarizing conditions.

Testosterone incubation of naïve murine $\mathrm{T}$ cells under both Th1-polarizing $\left[F_{(3,25)}=25.59, P<0.0001\right]$ and Th17-polarizing $\left[F_{(3,25)}=13.33, P<0.0001\right]$ conditions resulted in decreased cell differentiation. Only the 100 nmol/L concentration significantly decreased Th17 cell counts $(P<0.0001)$; however, all tested $\mathrm{T}$ 

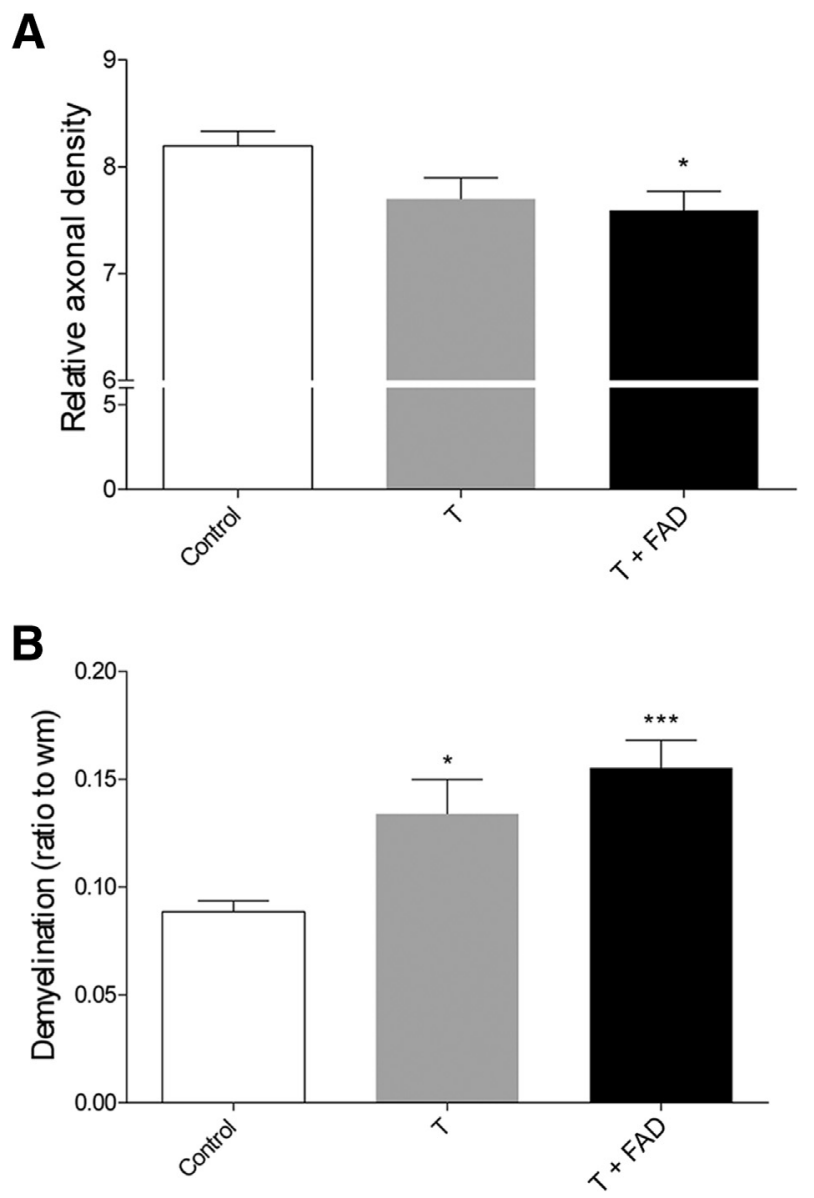

Figure 2 Effects of testosterone $(T)$ and $T+$ fadrozole (FAD) on spinal cord histological examination in chronic experimental autoimmune encephalomyelitis. A: Treatment with s.c. $T+$ FAD decreases the relative axonal density in the murine spinal cord. B: Treatment with s.c. T FAD and, to a lesser degree, $T$ increases demyelination relative to total spinal cord white matter (wm). Data are expressed as means \pm SEM. $n=8$ to 10 mice per condition. ${ }^{*} P<0.05$ and ${ }^{* * *} P<0.001$ versus control. $P=$ 0.0285 (A, T + FAD versus control); $P=0.0001$ (B, T + FAD versus control); $P=0.0171$ (B, T versus control).

concentrations $-1 \mathrm{nmol} / \mathrm{L}(P=0.0271), 10 \mathrm{nmol} / \mathrm{L}$ $(P<0.0001)$, and $100(P<0.0001) \mathrm{nmol} / \mathrm{L}$-inhibited Th1 differentiation with respect to untreated control (Figure 3, A and B). This differentiation effect was independent of aromatization: $5 \mu \mathrm{mol} / \mathrm{L}$ FAD cotreatment did not alter T effects on Th1 and Th17 differentiation, with $\mathrm{T}+\mathrm{FAD}$ treatments revealing an overall significant difference in both Th1-polarizing $\left[F_{(3,8)}=15.36, P=0.0011\right]$ and Th17polarizing $\left[F_{(3,8)}=7.206, P=0.0116\right]$ conditions. Follow-up tests showed results equivalent to those from Tonly experiments: the addition of 10 and $100 \mathrm{nmol} / \mathrm{L} \mathrm{T}$ in the presence of FAD significantly decreased Th1 differentiation $(P=0.0009$ and $P=0.0043$, respectively), whereas only treatment with $100 \mathrm{nmol} / \mathrm{L} \mathrm{T}$ in the presence of $\mathrm{FAD}$ significantly decreased Th17 differentiation $(P=0.01)$ (Figure 3, C and D). There were no significant differences between FAD and no-FAD conditions of the same testosterone concentration in either Th1 or Th17 differentiations
(Th1: $10 \mathrm{nmol} / \mathrm{L} P=0.9913,100 \mathrm{nmol} / \mathrm{L} P>0.9999$; Th17: $10 \mathrm{nmol} / \mathrm{L} P=0.9954,100 \mathrm{nmol} / \mathrm{L} P=0.7492$ ). Alternatively, $\mathrm{T}$ treatment had no effect on murine Treg differentiation (data not shown).

\section{$T+F A D$, but Not T, Treatment Increases Cell Death by 0xidative Stress in in Vitro Human Neuron Culture}

In an effort to both investigate whether the androgenic effect seen in vivo could be the result of direct hormone action on neural processes and to translate the observed in vivo effects of androgenic treatment on neurodegeneration to the human system, induced pluripotent stem cell-derived neurons were subjected to oxidative stress via hydrogen peroxide before the application of vehicle, FAD, or varying concentrations of $\mathrm{T}$ with and without FAD. Cells were then assessed for cell death via a 7 -aminoactinomycin D viability assay.

$\mathrm{T}$ or $\mathrm{T}+\mathrm{FAD}$ incubation of hydrogen peroxide - stressed human neurons reflected in vivo murine data $\left[F_{(7,68)}=\right.$ $8.816, P<0.0001]$. Cotreatment of FAD with $10 \mathrm{nmol} / \mathrm{L} \mathrm{T}$ $(P=0.0053), 100 \mathrm{nmol} / \mathrm{L} \mathrm{T}(P=0.0274)$, and $1 \mu \mathrm{mol} / \mathrm{L} \mathrm{T}$ $(P<0.0001)$ all significantly exacerbated cell death by oxidative stress, though neither FAD alone nor any T-only concentration altered degeneration (Figure 4).

\section{Discussion}

From the present data, it is clear that androgens act differentially to affect the neurodegenerative and neuroinflammatory phases of EAE. In our models, testosterone administered to female mice or applied to female-derived neurons is likely to be at least partly converted into estradiol due to endogenous or neuronal production of aromatase. ${ }^{37,38}$ Our studies employ the aromatase inhibitor fadrozole to prevent this. Hence, in the context of the EAE and in vitro neuronal experiments, $T+F A D$ treatments provide a pure androgenic effect and T treatments one of mixed estradiol/ testosterone. No such evidence of T-cell production of aromatase has been found.

When female mice are prophylactically treated from the day of Mog immunization, androgens significantly alleviate the acute inflammatory phase of EAE, whereas treatment without fadrozole results in an intermediate effect on disease course with respect to control in the acute condition. However, as treatment and disease progress past the end of the acute phase of peak inflammation and into the chronic phase, ${ }^{39}$ these phenotypes converge. Despite these divergent effects on acute disease course, T-cell spinal cord infiltration did not differ between hormone or control treatment, perhaps due to the different ways in which testosterone and estradiol affect neuroinflammatory processes. Further isolation of the inflammation recruitment via adoptive transfer did not yield any further clarity, with hormonal effects on donor cells yielding no EAE induction and 

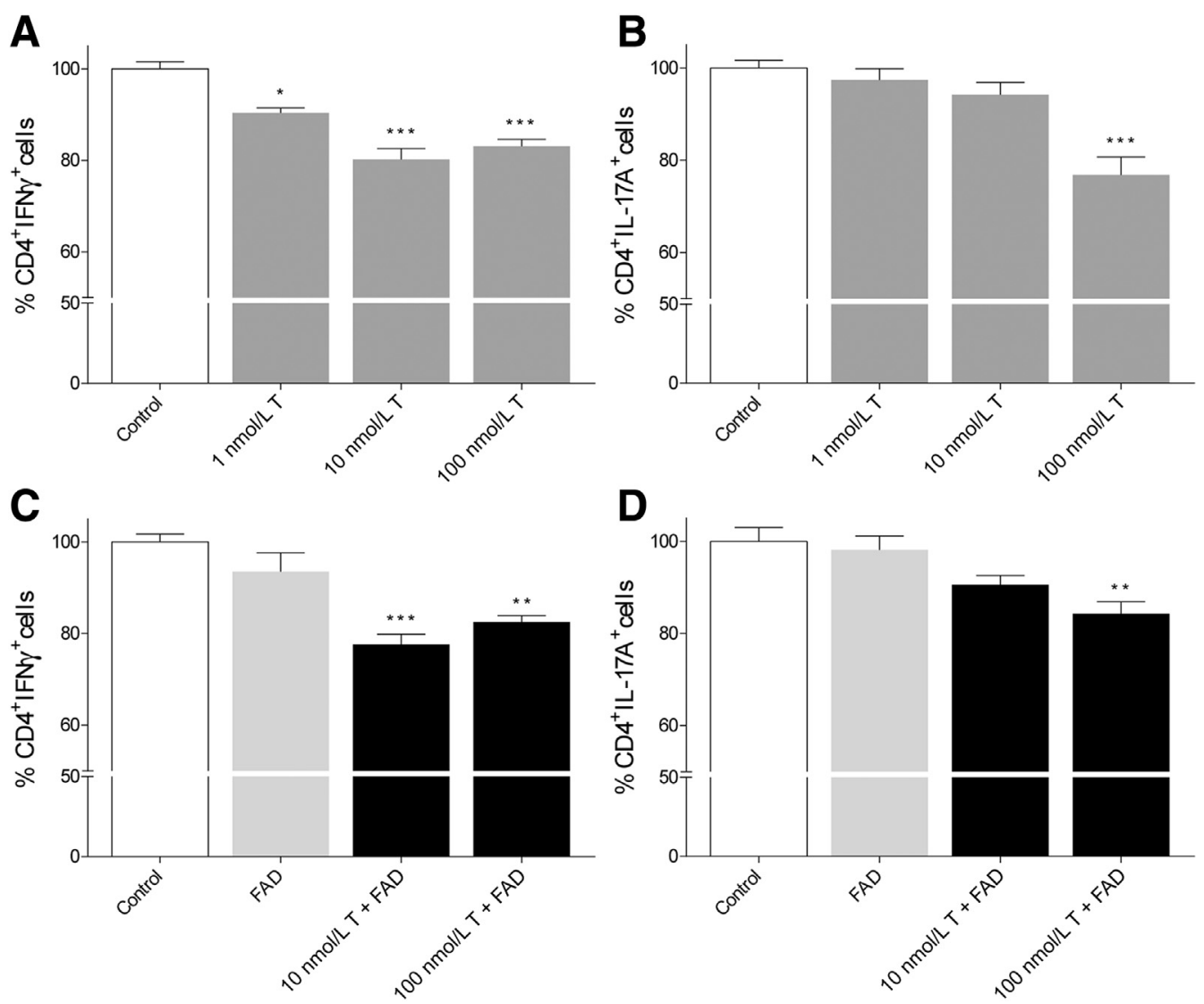

Figure 3 Testosterone (T) decreases murine Th1/Th17 differentiation in vitro. A: Application of various levels of T at time of naïve T cell for seeding results in an overall significant difference between treatment groups during Th1 cell differentiation. Follow-up Sidak multiple comparisons tests reveal significant reductions in Th1 differentiation at all concentrations of T treatment compared with control. B: Th17 differentiation in the presence of T shows an overall significant difference, with only the $100 \mathrm{nmol} / \mathrm{L}$ concentration significantly curtailing differentiation with respect to control. C: Although there is an overall significant difference between treatment groups during Th1 differentiation, the addition of $5 \mu \mathrm{mol} / \mathrm{L}$ fadrozole (FAD) does not affect Th1 differentiation without coapplication of T. Follow-up Sidak multiple comparisons tests show that conpresent molecular aromatase inhibition reduces Th1 differentiation in both the $10 \mathrm{nmol} / \mathrm{L}$ and $100 \mathrm{nmol} / \mathrm{L} \mathrm{T}$ application conditions compared with control. D: Th17 differentiation in the presence of testosterone shows an overall significant difference. The addition of FAD $5 \mu \mathrm{mol} / \mathrm{L}$ does not affect Th17 differentiation without the coapplication of T. T + FAD reduces Th17 differentiation solely with the T 100 $\mathrm{nmol} / \mathrm{L}$ treatment condition. Data were pooled from three independent experiments, normalized to their respective controls, and are expressed as means $\pm \mathrm{SEM}$. $n=3$ per group. ${ }^{*} P<0.05,{ }^{*} P<0.01$, and ${ }^{* * *} P<0.001$ versus control. $P=0.0271(\mathbf{A}, 1 \mathrm{nmol} / \mathrm{L} \mathrm{T}$ versus control); $P=0.0009$ (C, $10 \mathrm{nmol} / \mathrm{L} \mathrm{T}+\mathrm{FAD}$ versus control); $P=0.0043$ (C, $100 \mathrm{nmol} / \mathrm{L} \mathrm{T}+\mathrm{FAD}$ versus control); $P=0.01$ (D, $100 \mathrm{nmol} / \mathrm{L} \mathrm{T}+\mathrm{FAD}$ versus control). IFN, interferon.

no differences in spinal cord infiltrates along with no differences in disease course after in vivo rechallenge. That the $\mathrm{T}$ treatment group, assumed to be a mixture of testosterone and estradiol due to endogenous aromatization, had a qualitatively and nonsignificantly worse disease course and macrophage infiltration lies in stark contrast to findings from previous studies demonstrating that estradiol and other estrogens ameliorate both disease course in an adoptive transfer $\operatorname{model}^{40,41}$ and spinal cord infiltrates in general. $^{21,25,42}$

As our and others' in vitro data demonstrate, testosterone decreases differentiation to autoreactive, proinflammatory $\mathrm{T}$ cells, that is, Th1 and Th17 cells, independent of aromatization. ${ }^{27,43}$ Estradiol, on the other hand, has been shown to mediate neuroinflammation via the recruitment of lymphocyte infiltrates into the central nervous system. ${ }^{24,42}$ Thus, a high androgen and low estrogen condition, as in our androgenic group, may beneficially skew the Th1/Th17-toTreg ratio toward Treg cells (though our experiments fail to replicate data showing a testosterone-induced increase of Treg differentiation), but a lack of estradiol within the system thus fails to beneficially alter infiltration. Unfortunately, this hypothesis has yet to be tested.

Converse to its beneficial effects on the acute phase, therapeutic treatment with testosterone and fadrozole exacerbates the chronic, neurodegenerative phase of EAE, indicating an androgenic mechanism of disease exacerbation. This is supported by our findings on murine spinal cord pathology, namely increased demyelination and decreased axonal density, and translated to the human system via an in vitro 7-aminoactinomycin D viability assay demonstrating increased neuronal death in response to oxidative stress by increasing androgen levels. Although this dosedependent exacerbation of androgenic effects to oxidative 


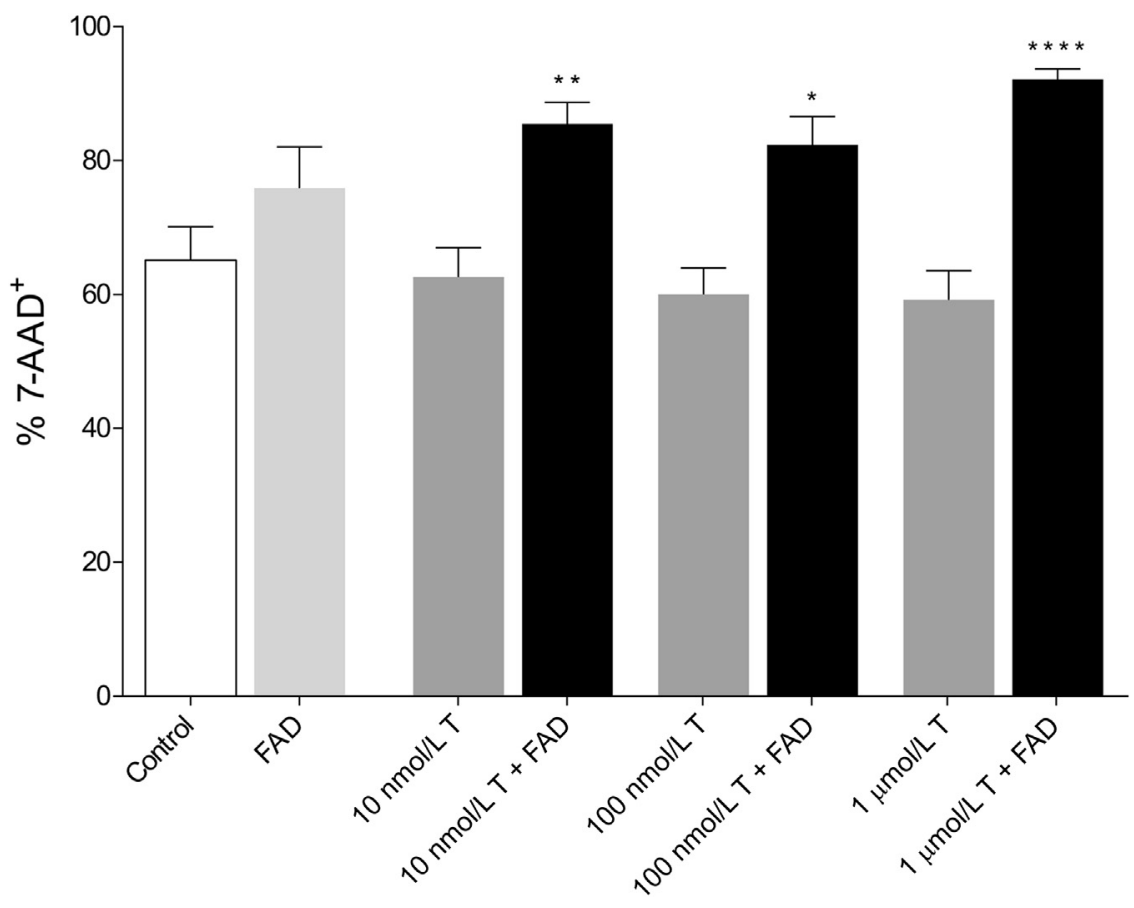

Figure 4 Testosterone + fadrozole ( $T$ + FAD), but not $T$ monotherapy, after treatment exacerbates neuronal cell death induced by oxidative stress. With hormone treatments applied 4 to 5 hours into 24-hour incubation with $15 \mu \mathrm{mol} / \mathrm{L}$ $\mathrm{H}_{2} \mathrm{O}_{2}$, there is a significant interaction between treatment effect (\% 7-aminoactinomycin $\mathrm{D}^{+}$) and cell death. Follow-up Sidak multiple comparisons tests show that treatment with $\mathrm{T}$ alone reveals neither a significant alleviation nor exacerbation of apoptosis compared with control. Alternatively, cotreatment with $5 \mu \mathrm{mol} / \mathrm{L}$ FAD at all tested T concentrations results in a significant exacerbation of cell death compared with control. Treatment with fadrozole alone is insufficient to increase cell death. Data were pooled from three independent experiments and are expressed as means \pm SEM. $n \geq 3$ per group. ${ }^{*} P<0.05$, $* * P<0.01$, and $* * * * P<0.0001$ versus control. $P=0.0053(10 \mathrm{nmol} / \mathrm{L} \mathrm{T}+\mathrm{FAD}$ versus control); $P=0.0274(100 \mathrm{nmol} / \mathrm{L} T+$ FAD versus control $)$. 7-AAD, 7-aminoactinomycin D. assault after treatment in vitro is in line with those from previous studies, ${ }^{13}$ ours is the first experiment to replicate this effect with the aromatizable, endogenously found androgen testosterone. Therefore, it was revealed that the presence of fadrozole, or possibly another aromatase inhibitor, is crucial for the observed effect of testosterone on induced pluripotent stem cell-derived human neurons, indicating that these female neurons produce aromatase and are able to facilitate the conversion of testosterone to estradiol in vitro. The presence of aromatase activity here may be unsurprising, as the protective properties of aromatase have been described, though not in the process of MS, ${ }^{32,44-46}$ and various studies have found ubiquitous aromatase expression within both the human brain ${ }^{38}$ and cultured murine spinal motor neurons. ${ }^{37}$ Furthermore, though estrogens are generally considered to confer neuroprotection, ${ }^{22,23}$ our testosterone-only treatment groups both in vivo and in vitro displayed a disease course and cell death ratio nearly identical to that of control. This finding may have been due to a congruent increase in testosterone along with estradiol as a result of testosterone treatment and endogenous aromatization, leading to an intermediate effect due to the opposition of androgenic and estrogenic processes. Thus, although findings from previous research has yet to reach consensus regarding the effects of androgens on neurodegeneration, ${ }^{13-15,23,29-31,44}$ our murine EAE and human in vitro evidence supports the hypothesis of an androgenic exacerbation of neurodegeneration in the context of MS.

Though the procured data provide evidence for differential androgenic and estrogenic effects on neuroinflammation and neurodegeneration in the context of EAE, the mechanism by which these effects are accomplished has not yet been elucidated. Indeed, our data do not indicate the source of neurodegeneration in vivo, whether the process itself is a primary symptom of EAE or secondary to demyelination. ${ }^{47}$ However, our in vitro data suggest that despite the unknown etiology, androgens can act directly on neurons to exacerbate the neurodegenerative process. It is also interesting to note that although androgen molecules mediate these deleterious effects, either estrogen or androgen receptors may be required: though fadrozole blocks the endogenous conversion of testosterone to estradiol, various androgens, such as the ADIOL and dihydrotestosterone activation of estrogen receptor $\beta$, have been known to activate estrogen receptors. ${ }^{25,48}$

In all, the data presented are the first to show differential effects of androgens on the neuroinflammatory and neurodegenerative processes of EAE, as is evident in timed hormone treatments targeting the acute and chronic phases of the disease. Spinal cord sections procured from these experiments, as well as in vitro T-cell differentiations under Th1- and Th17-polarizing conditions, propose a model whereby testosterone decreases the Th1 and Th17 cell induction in an aromatase-independent manner without affecting the total T-cell spinal cord infiltrate. Similarly, silver staining and the apoptosis assay of primary human neurons suggest that androgens exacerbate neurodegeneration in an environment of EAE and oxidative stress. Although the mechanisms of these hormonal processes remain to be explored, our study provides strong evidence of differential hormonal effects on the phases of EAE. As such, it is pertinent for future studies to dissociate between the neurodegenerative and neuroinflammatory 
processes of MS and EAE to more accurately explore the underpinnings of the disease. Such evidence may indeed prove vitally important when considering hormone treatments for MS patients. Furthermore, such a dissociation hints at a plausible explanation for the high MS prevalence among women, lacking androgenic inflammatory protection, but accelerated disease course among men, incurring higher levels of testosterone and possible oversaturation of local aromatization, in the MS population.

\section{Acknowledgments}

We thank Xiomara Pedreiturria for her invaluable expertise and Alexander Duscha for his continued support and assistance.

A.H. is the guarantor of this work and, as such, has full access to all data in the study and takes responsibility for the integrity of the data and the accuracy of the data analysis.

\section{Supplemental Data}

Supplemental material for this article can be found at http://dx.doi.org/10.1016/j.ajpath.2017.03.006.

\section{References}

1. Bove R, Chitnis T: Sexual disparities in the incidence and course of MS. Clin Immunol 2013, 149:201-210

2. Chao MJ, Herrera BM, Ramagopalan SV, Deluca G, Handunetthi L, Orton SM, Lincoln MR, Sadovnick AD, Ebers GC: Parent-of-origin effects at the major histocompatibility complex in multiple sclerosis. Hum Mol Genet 2010, 19:3679-3689

3. Du S, Itoh N, Askarinam S, Hill H, Arnold AP, Voskuhl RR: XY sex chromosome complement, compared with $\mathrm{XX}$, in the CNS confers greater neurodegeneration during experimental autoimmune encephalomyelitis. Proc Natl Acad Sci U S A 2014, 111:2806-2811

4. Costenbader KH, Gay S, Alarcón-Riquelme ME, Iaccarino L, Doria A: Genes, epigenetic regulation and environmental factors: which is the most relevant in developing autoimmune diseases? Autoimmun Rev 2012, 11:604-609

5. Voskuhl RR, Gold SM: Sex-related factors in multiple sclerosis susceptibility and progression. Nat Rev Neurol 2012, 8:255-263

6. Pakpoor J, Goldacre R, Schmierer K, Giovannoni G, Goldacre MJ: Testicular hypofunction and multiple sclerosis risk: a record-linkage study. Ann Neurol 2014, 76:625-628

7. Bove R, Musallam A, Healy BC, Raghavan K, Glanz BI, Bakshi R, Weiner H, De Jager PL, Miller KK, Chitnis T: Low testosterone is associated with disability in men with multiple sclerosis. Mult Scler 2014, 20:1584-1592

8. Sicotte NL, Liva SM, Klutch R, Pfeiffer P, Bouvier S, Odesa S, Wu TC, Voskuhl RR: Treatment of multiple sclerosis with the pregnancy hormone estriol. Ann Neurol 2002, 52:421-428

9. Voskuhl RR, Wang H, Wu TCJ, Sicotte NL, Nakamura K, Kurth F, Itoh N, Bardens J, Bernard JT, Corboy JR, Cross AH, Dhib-Jalbut S, Ford CC, Frohman EM, Giesser B, Jacobs D, Kasper LH, Lynch S, Parry G, Racke MK, Reder AT, Rose J, Wingerchuk DM, MacKenzieGraham AJ, Arnold DL, Tseng CH, Elashoff R: Estriol combined with glatiramer acetate for women with relapsing-remitting multiple sclerosis: a randomised, placebo-controlled, phase 2 trial. Lancet Neurol 2016, 15:35-46
10. Huang G, Wharton W, Travison TG, Ho MH, Gleason C, Asthana S, Bhasin S, Basaria S: Effects of testosterone administration on cognitive function in hysterectomized women with low testosterone levels: a dose-response randomized trial. J Endocrinol Invest 2014, 38:455-461

11. Kurth F, Luders E, Sicotte NL, Gaser C, Giesser BS, Swerdloff RS, Montag MJ, Voskuhl RR, Mackenzie-Graham A: Neuroprotective effects of testosterone treatment in men with multiple sclerosis. Neuroimage Clin 2014, 4:454-460

12. Sicotte NL, Giesser BS, Tandon V, Klutch R, Steiner B, Drain AE, Shattuck DW, Hull L, Wang H-J, Elashoff RM: Testosterone treatment in multiple sclerosis: a pilot study. Arch Neurol 2007, 64:683-688

13. Holmes S, Abbassi B, Su C, Singh M, Cunningham RL: Oxidative stress defines the neuroprotective or neurotoxic properties of androgens in immortalized female rat dopaminergic neuronal cells. Endocrinology 2013, 154:4281-4292

14. Orlando R, Caruso A, Molinaro G, Motolese M, Matrisciano F, Togna G, Melchiorri D, Nicoletti F, Bruno V: Nanomolar concentrations of anabolic-androgenic steroids amplify excitotoxic neuronal death in mixed mouse cortical cultures. Brain Res 2007, 1165:21-29

15. Nguyen TV, Jayaraman A, Quaglino A, Pike CJ: Androgens selectively protect against apoptosis in hippocampal neurones. J Neuroendocrinol 2010, 22:1013-1022

16. Palaszynski KM, Liu H, Loo KK, Voskuhl RR: Estriol treatment ameliorates disease in males with experimental autoimmune encephalomyelitis: implications for multiple sclerosis. J Neuroimmunol 2004, 149:84-89

17. MacKenzie-Graham AJ, Rinek GA, Avedisian A, Morales LB, Umeda E, Boulat B, Jacobs RE, Toga AW, Voskuhl RR: Estrogen treatment prevents gray matter atrophy in experimental autoimmune encephalomyelitis. J Neurosci Res 2012, 90:1310-1323

18. Morales LBJ, Loo KK, Liu H, Peterson C, Tiwari-Woodruff S, Voskuhl RR: Treatment with an estrogen receptor $\alpha$ ligand is neuroprotective in experimental autoimmune encephalomyelitis. J Neurosci 2006, 26:6823-6833

19. Haghmorad D, Amini AA, Mahmoudi MB, Rastin M, Hosseini M, Mahmoudi M: Pregnancy level of estrogen attenuates experimental autoimmune encephalomyelitis in both ovariectomized and pregnant C57BL/6 mice through expansion of Treg and Th2 cells. J Neuroimmunol 2014, 277:85-95

20. Wisdom AJ, Cao Y, Itoh N, Spence RD, Voskuhl RR: Estrogen receptor- $\beta$ ligand treatment after disease onset is neuroprotective in the multiple sclerosis model. J Neurosci Res 2013, 91:901-908

21. Wu W, Tan X, Dai Y, Krishnan V, Warner M, Gustafsson J-Å: Targeting estrogen receptor $\beta$ in microglia and $T$ cells to treat experimental autoimmune encephalomyelitis. Proc Natl Acad Sci U S A 2013, 110:3543-3548

22. Bains M, Cousins JC, Roberts JL: Neuroprotection by estrogen against $\mathrm{MPP}+$-induced dopamine neuron death is mediated by ER $\alpha$ in primary cultures of mouse mesencephalon. Exp Neurol 2007, 204:767-776

23. Park SY, Tournell C, Sinjoanu RC, Ferreira A: Caspase-3- and calpainmediated tau cleavage are differentially prevented by estrogen and testosterone in beta-amyloid-treated hippocampal neurons. Neuroscience 2007, 144:119-127

24. Lélu K, Laffont S, Delpy L, Paulet P-E, Périnat T, Tschanz SA, Pelletier L, Engelhardt B, Guéry J-C: Estrogen receptor $\alpha$ signaling in $\mathrm{T}$ lymphocytes is required for estradiol-mediated inhibition of Th1 and Th17 cell differentiation and protection against experimental autoimmune encephalomyelitis. J Immunol 2011, 187:2386-2393

25. Saijo K, Collier JG, Li AC, Katzenellenbogen JA, Glass CK: An ADIOL-ER $\beta-C t B P$ transrepression pathway negatively regulates microglia-mediated inflammation. Cell 2011, 145:584-595

26. Liva SM, Voskuhl RR: Testosterone acts directly on CD4+ T lymphocytes to increase IL-10 production. J Immunol 2001, 167: 2060-2067

27. Fijak M, Schneider E, Klug J, Bhushan S, Hackstein H, Schuler G, Wygrecka M, Gromoll J, Meinhardt A: Testosterone replacement effectively inhibits the development of experimental autoimmune 
orchitis in rats: evidence for a direct role of testosterone on regulatory T cell expansion. J Immunol 2011, 186:5162-5172

28. Vignozzi L, Cellai I, Santi R, Lombardelli L, Morelli A, Comeglio P, Filippi S, Logiodice F, Carini M, Nesi G, Gacci M, Piccinni M-P, Adorini L, Maggi M: Antiinflammatory effect of androgen receptor activation in human benign prostatic hyperplasia cells. J Endocrinol 2012, 214:31-43

29. Estrada M, Varshney A, Ehrlich BE: Elevated testosterone induces apoptosis in neuronal cells. J Biol Chem 2006, 281:25492-25501

30. Hammond J, Le Q, Goodyer C, Gelfand M, Trifiro M, LeBlanc A: Testosterone-mediated neuroprotection through the androgen receptor in human primary neurons. J Neurochem 2001, 77:1319-1326

31. Nguyen TV, Yao M, Pike CJ: Androgens activate mitogen-activated protein kinase signaling: role in neuroprotection. J Neurochem 2005 , 94:1639-1651

32. McCullough LD, Blizzard K, Simpson ER, Oz OK, Hurn PD: Aromatase cytochrome P450 and extragonadal estrogen play a role in ischemic neuroprotection. J Neurosci 2003, 23:8701-8705

33. Haghikia A, Jörg S, Duscha A, Berg J, Manzel A, Waschbisch A, Hammer A, Lee D-H, May C, Wilck N, Balogh A, Ostermann AI, Schebb NH, Akkad DA, Grohme DA, Kleinewietfeld M, Kempa S, Thöne J, Demir S, Müller DN, Gold R, Linker RA: Dietary fatty acids directly impact central nervous system autoimmunity via the small intestine. Immunity 2015, 43:817-829

34. Chronowska E, Tománek M, Kott T: Effect of aromatase inhibitor (fadrozole) on proliferation, estradiol production and telomerase activity in pig granulosa cells in vitro. Czech J Anim Sci 2009, 54:566-574

35. Massa MG, Gisevius B, Hirschberg S, Hinz L, Schmidt M, Gold R, Prochnow N, Haghikia A: Multiple sclerosis patient-specific primary neurons differentiated from urinary renal epithelial cells via induced pluripotent stem cells Kleinschnitz C, editor. PLoS One 2016, 11: e0155274

36. Kleinewietfeld M, Hafler DA: Regulatory $\mathrm{T}$ cells in autoimmune neuroinflammation. Immunol Rev 2014, 259:231-244

37. Rakotoarivelo C, Petite D, Lambard S, Fabre C, Rouleau C, Lumbroso S, de Weille J, Privat A, Carreau S, Mersel M: Receptors to steroid hormones and aromatase are expressed by cultured motoneurons but not by glial cells derived from rat embryo spinal cord. Neuroendocrinology 2005, 80:284-297

38. Biegon A: In vivo visualization of aromatase in animals and humans. Front Neuroendocrinol 2016, 40:42-51

39. Day MJ: Histopathology of EAE. Experimental Models of Multiple Sclerosis. Boston, MA, Springer US, 2005, pp. 25-43

40. Bebo BF, Fyfe-Johnson A, Adlard K, Beam AG, Vandenbark AA, Offner H: Low-dose estrogen therapy ameliorates experimental autoimmune encephalomyelitis in two different inbred mouse strains. J Immunol 2001, 166:2080-2089

41. Kim S, Liva SM, Dalal MA, Verity MA, Voskuhl RR: Estriol ameliorates autoimmune demyelinating disease: implications for multiple sclerosis. Neurology 1999, 52:1230-1238

42. Lélu K, Delpy L, Robert V, Foulon E, Laffont S, Pelletier L, Engelhardt B, Guéry J-C: Endogenous estrogens, through estrogen receptor $\alpha$, constrain autoimmune inflammation in female mice by limiting CD4+ T-cell homing into the CNS. Eur J Immunol 2010, 40: 3489-3498

43. Kissick HT, Sanda MG, Dunn LK, Pellegrini KL, On ST, Noel JK, Arredouani MS: Androgens alter T-cell immunity by inhibiting T-helper 1 differentiation. Proc Natl Acad Sci U S A 2014, 111:9887-9892

44. Lau C-F, Ho Y-S, Hung CH-L, Wuwongse S, Poon C-H, Chiu K, Yang X, Chu L-W, Chang RC-C: Protective effects of testosterone on presynaptic terminals against oligomeric $\beta$-amyloid peptide in primary culture of hippocampal neurons. Biomed Res Int 2014, 2014:103906

45. Garcia-Segura LM, Veiga S, Sierra A, Melcangi RC, Azcoitia I: Aromatase: a neuroprotective enzyme. Prog Neurobiol 2003, 71:31-41

46. Saldanha CJ, Duncan KA, Walters BJ: Neuroprotective actions of brain aromatase. Front Neuroendocrinol 2009, 30:106-118

47. Tsunoda I, Fujinami RS: Inside-out versus outside-in models for virus induced demyelination: axonal damage triggering demyelination. Springer Semin Immunopathol 2002, 24:105-125

48. Lund TD, Hinds LR, Handa RJ: The androgen $5 \alpha$-dihydrotestosterone and its metabolite $5 \alpha$-androstan- $3 \beta, 17 \beta$-diol inhibit the hypothalamopituitary-adrenal response to stress by acting through estrogen receptor $\beta$-expressing neurons in the hypothalamus. J Neurosci 2006, 26 : 1448-1456 